\title{
What makes silica toxic?
}

\author{
N Bagchi
}

\begin{abstract}
Published data suggest that particle charge could be related to its toxicity. Respirable particles containing silica were therefore collected in foundries and their charge measured. These particles carried high levels of positive charge that were related to low humidity. Incubating these particles with pulmonary macrophages from mice produced detectable activities of collagenase, a precursor of silicosis. These experiments confirm that the toxicity of silica particles is likely to be because of the positive charge they carry.
\end{abstract}

Silicosis is caused by inhaling excessive quantities of respirable silica bearing dusts. The disease, once initiated, is irreversible and progressive. Although this has been recognised for 2000 years, it still remains one of the most common occupational diseases. The National Institute of Occupational Safety and Health estimates that 1200000 workers are exposed to free silica in the United States and it is common for $15 \%$ of the exposed workforce eventually to develop silicosis. Although most pathogenic mechanisms have received attention, what makes silica toxic still remains an enigma. As long as this is unresolved, the continued efforts of the medical and technical communities to reduce the incidence of silicosis by medical surveillance, pulmonary function tests, $x$ ray film examinations, and improved environmental control could be frustrated.

Particles capable of reaching the alveolar areas of the lungs are termed "respirable" and are usually from 0.5 to $5 \mu \mathrm{m}$ in aerodynamic diameter. The basic mechanism of removal consists of these particles being engulfed by alveolar macrophages and then carried to the mucociliary system to be cleared. The rate of clearance depends on the quantity of the particles and their toxicity. Agricola, in the 15th century, noted that diseases of miners were related to the dryness of mines. ${ }^{1}$ Heppleston concluded, on the basis of his experiments, that it was the surface of the

Department of the Environment, Lodi Road, New Delhi 110003, India N Bagchi silica dust that was primarily involved in the disease. ${ }^{2}$ Kosztolanyi et al observed that the severity of tissue lesions caused by 1 to $5 \mu \mathrm{m}$ diameter particles was related to their electrophoretic mobility. ${ }^{3}$ These findings suggested that it could be the particle charge that made silica toxic. The present study investigates this possibility.

\section{Material and methods}

The experiment had two parts: the first was the measurement of charge on respirable particles and the second was the incubation of these particles with alveolar macrophages to check for the presence of collagenase. Charge measurements were made in the cleaning rooms of foundries using either silica or non-silica sand. The particles in the cleaning rooms were always quite dry and their concentrations in the air were higher than in other areas in the foundries: it was therefore easier for measurements to be taken.

The accepted method for sampling respirable dust is by using the Dorr-Oliver $10 \mathrm{~mm}$ nylon cyclone connected to a pump at a flow rate of $1.71 / \mathrm{m}$. The cyclone and pump used in the study were made by Mines Safety Appliances (Pittsburgh, PA) and were run at least in duplicate next to each other. One of these cyclones had an FWS-B polyvinyl chloride filter (Mines Safety Appliances) and the other had a $0.45 \mu \mathrm{m}$ porosity silver membrane (Millipore Corporation, Bedford, MA). One end of a fine polyethylene coated copper wire was inserted into the cyclone from its outlet and made contact with the silver membrane and the other end was connected to an electrometer (model 610B, Keithley Instruments, Cleveland, $\mathrm{OH}$ ). The electrometer was calibrated against a standard voltage before each experiment. The cyclone, with the silver membrane, was placed in a box made from press fitted copper sheets to give a $6 \mathrm{~cm}$ hole at the top for entry of ambient air, at the same time minimising the effect of extraneous charges. The electrometer had a range from $10^{-5}$ to $10^{-13}$ coulombs, either positive or negative, for charge and 0.3 to $10^{-13}$ amperes in the current mode. The charge accumulated was measured for several one minute periods after the pump was turned on. The periods were timed with a stopwatch and the average charge values recorded. The FWS-B filters were weighed before and after sampling on a Cahn electrobalance (model 4700, Ventron Inc, Paramount, 
CA). During sampling, the temperature and dew point were measured using a dew point meter (Alnor, Niles, ILL) and the per cent relative humidity was read from a psychrometric chart. The silica content in the sample collected on the FWS-B filter was determined by $x$ ray diffraction using first an automatic 2-theta scan, then by a count at the major and minor peaks at 26.7 and 20.85 degrees (Phillips XRG 3000 with APD controller and printout, Mahwah, $\mathrm{NJ}$ ). Each run was standardised against a minus $5 \mu \mathrm{m}$ "minusil" sample. ${ }^{4}$

Enzyme studies were with pulmonary macrophage (PM) cultures from six to 12 week old female swiss mice (Biolabs, St Paul, MN). All cells were cultured in Medium-199 (Gibco, Grand Island, NY) supplemented with $10 \%$ heat inactivated fetal calf serum (HIFCS) (Gibco), penicillin (100 units/ml), streptomycin $(100 \mu \mathrm{g} / \mathrm{ml})$ enriched with dextrose, pyruvate, glutamine, and non-essential amino acids (M-199 [+] w/HIFCS). The cells were incubated at $37^{\circ} \mathrm{C}$ in a humid atmosphere of $5 \%$ carbon dioxide. Macrophages were obtained from mice by mincing their lungs over nylon stocking material and filtering down with M-199 [+] w/HIFCS. Cell suspensions were centrifuged at $150 \mathrm{~g}$ for 10 minutes. The pellet was resuspended in $10 \mathrm{ml}$ ammonium chloride red blood cell hypotonic lysing buffer for 10 minutes at $4^{\circ} \mathrm{C}$, recentrifuged, and washed twice with MEM F-14 (Gibco). Cell counts were obtained with a haemocytometer and adjusted to $10^{6}$ macrophages/ $\mathrm{ml}$ in $\mathrm{M}-199[+] \mathrm{w} / \mathrm{HIFCS}$. A glass cover slip was placed in each well of a Costar cluster dish and $1 \mathrm{ml}$ of the cell suspension was added per well. After three hours of incubation the supernatants were aspirated, the monolayers were washed twice with'warm phosphate buffered saline and $1 \mathrm{ml}$ of $\mathrm{M}-199[+] \mathrm{w} /$ HIFCS was added per well. Adherent cells consisted of about $85 \%$ PMs, as found by non-specific esterase and peroxidase stains. ${ }^{56}$ Respirable particles collected on the silver membrane were washed down with distilled water to a predetermined volume and kept suspended through constant shaking. A measured amount of this suspension was added to PM cultures in the well, in duplicate, to make up $0.035 \mathrm{mg}$ respirable dust addition per $10^{6} \mathrm{PMs}$. After 24 hours the supernatant was analysed for collagenase using ${ }^{14} \mathrm{C}$ glycine labelled collagen fibres (courtesy National Institute of Health, Bethesda, MD). Two hundred microlitres of $50 \mathrm{mM}$ Tris $\mathrm{HCl}(\mathrm{pH} 7.5), 5 \mathrm{mM}$ $\mathrm{CaCl}_{2}$, and $0.5 \mathrm{ml}$ of media from culture were added to $300 \mu \mathrm{g}$ of the labelled material. This was incubated for 16 hours at $35^{\circ} \mathrm{C}$ and the unreacted fibres were removed by ultracentrifugation (Beckman Microfuge). The supernatant was pipetted off and the button suspended in $100 \mu \mathrm{l}$ of tris $\mathrm{HCl}$ ( $\mathrm{pH} 7 \cdot 5$ ). This was added to $10 \mathrm{ml}$ of scintillation fluid (Packard Inc, Chicago, ILL) and the amount of labelled material remaining was read off on a liquid scintillation counter (model LS-100C, Beckman). The extent of non-specific degradation was checked by adding $0.01 \%$ trypsin.

\section{Results}

Charge measurements were made on different days over a five month period in the cleaning rooms of grey iron foundries. Five of these were in the same foundry but all used silica sand in their moulding process. Measurements were also taken on one day in an aluminium foundry that used mainly olivine (magnesium orthosilicate) in its process. Table 1 gives the results.

Table 2 gives results of the cell culture studies.

\section{Discussion}

Silica is known to be cytotoxic to the alveolar macrophage and the death of the macrophage has been suggested to be intimately related to the genesis of silicotic fibrosis. The pulmonary reaction to silica has four distinct events: ${ }^{2}$

(1) Necrosis of the macrophage that had taken up and liberated the silica particle.

(2) Continued production of macrophages to re-ingest silica particles.

(3) Formation of collagen.

(4) Hyalinisation.

The first and the third steps have been proposed to be closely linked in that the dying macrophage stimulates fibroblasts to lay down collagen. ${ }^{7}$ An examination of the reticular nodules showed these to be made up of macrophages, fibroblasts, and reticular fibrils. ${ }^{8}$ The reaction of macrophages, in combination with fibroblasts, may have evolved as a part of the body's defence mechanism. During the healing of wounds macrophages are required for the normal ingrowth of fibroblasts and for the production of

Table 1 Measurement of charge and of silica content

\begin{tabular}{|c|c|c|}
\hline & $\begin{array}{l}\text { Grey iron } \\
\text { foundry }\end{array}$ & $\begin{array}{l}\text { Aluminium } \\
\text { foundry }\end{array}$ \\
\hline Sampling period & $\begin{array}{l}22 \text { Jan- } \\
16 \text { June } 1980\end{array}$ & 29 May 1980 \\
\hline $\begin{array}{l}\text { Collection time }(\mathrm{h}) \\
\text { Respirable dust }\left(\mathrm{mg} / \mathrm{m}^{3}\right) \\
\text { Silica }(\%) \\
\text { Charge (coulombs } / 60 \mathrm{~s})\end{array}$ & $\begin{array}{l}4-7 \cdot 5 \\
1 \cdot 08-1 \cdot 52 \\
18 \cdot 4-23 \cdot 0 \\
10^{-7}-10^{-9} \\
\text { (positive) }\end{array}$ & $\begin{array}{l}4 \\
0.15 \\
0.2 \\
0.5 \times 10^{-8} \\
\text { (negative) }\end{array}$ \\
\hline Charge (coulombs/mg) & $\begin{array}{l}7 \cdot 8 \times 10^{-7}- \\
9 \cdot 2 \times 10^{-5}\end{array}$ & $3.3 \times 10^{-5}$ \\
\hline Humidity & $28-39$ & 58 \\
\hline
\end{tabular}

One coulomb equals $1.6 \times 10^{19}$ elementary charges and assuming that the respirable particles collected were all $1 \mu \mathrm{m}$ in aerodynamic that the respirable particles collected weried about $10^{6}$ elementary positive charges. The charge readings on silica were verified once pyste chectrometer: it read $0.02 \mu \mathrm{A}$. Because charge is the product of current and time, this value of current was equivalent to $1.2 \times 10^{-6}$ coulombs in a one minute period. 
Table 2 Extent of collagenase reaction measured by the radioactivity of unreacted collagen

\begin{tabular}{lll}
\hline & $\begin{array}{l}\text { Radioactivity in unreacted } \\
{ }^{14} \text { C labelled fibres (average counts) }\end{array}$ & $\begin{array}{l}\text { Degree of fibre } \\
\text { breakdown }\end{array}$ \\
\hline $\begin{array}{l}\text { Media with macrophage cultures with silica } \\
\text { Control (0.01\% trypsin) }\end{array}$ & 960 & $3000-960=2040$ \\
\hline
\end{tabular}

The standard amount of labelled fibre had 3000 counts.

collagen. In interstitial lung diseases-a group of nearly 130 different disorders-a derangement of alveolar structures normally exists, including fibrosis of the adjacent interstitium. This ultimately disturbs the structure of the lung parenchyma so that alveoli are no longer able to mediate gas exchange. It has been reported that most patients with idiopathic pulmonary fibrosis have detectable active collagenase in their bronchoalveolar lavage fluid. ${ }^{9}$ This indicates that the disease is progressive. Of special concern is the relation between macrophage secretory products and the synthesis and degradation of connective tissue components. Macrophages are stimulated by phagocytosis and are capable of secreting enzymes like collagenase that can degrade connective tissue. ${ }^{10}$ The enzymes have been detected in fluids from macrophage cultures, but not interstitially. This suggests that they are secreted rapidly and without intracellular storage when activated. ${ }^{11}$ The output of free macrophages in the body, however, is in response to the type of particle and the total load. ${ }^{12}$ In the present study, detectable activities of collagenase were found in samples when macrophages were incubated with silica particles that had positive charge (table 2).

The electrophoretic mobility (a measure of the charge) of particles has been shown to be proportional to the severity of pulmonary damage when tested intratracheally in rats. ${ }^{3}$ Pretreatment of quartz particles with polyvinylpyridine- $\mathrm{N}$-oxide (PVPNO) decreased the severity. ${ }^{13}$ The improvement resulted from insulation of the charge, a purely physical phenomenon, and the characteristic reaction occurred again when PVPNO was removed from the surface of the particles. In a second study, the zeta potential, another measure of the charge, was found to be close to $50 \mathrm{mV}$ for both asbestos and silica and the zeta potential of asbestos was proportional to the haemolysis of erythrocytes. ${ }^{14}$ It was found that surfactants reduced the zeta potential and also the toxicity of asbestos. It appears reasonable to conclude that the surfactants insulated the charge of the asbestos fibres. Both of these experiments indicate that charge of the particles is the property that imparts toxicity to a substance. Measurements of charge made in the present study always showed that silica particles carried positive values of a high magnitude (table 1). Whereas positive charge on particles appears to be a property that causes macrophages and fibroblasts to react in the characteristic manner, this reaction could be aggravated by the current generated by the positively charged particles. Current in the range of 0.01 to $15 \mu \mathrm{A}$ has been found to promote synthesis of collagen by fibroblasts. ${ }^{15} \mathrm{~A}$ measurement of current was made in the present study; $0.02 \mu \mathrm{A}$ was generated by the positively charged particles. Further, it has been reported that crysotile asbestos caused fibroblasts to lay down collagen directly without the activation by macrophages. ${ }^{16}$ This could be because the charge they carried generated a current in the critical range to elicit this reaction, possibly a potentiating mechanism of the disease. ${ }^{17}$

It has been known for some years that olivine, unlike silica, does not cause lung disease and the substitution of silica by olivine has been recommended as a method of control in foundries..$^{18}$ If positive charge on particles was indeed the causative factor in silicosis, there should be a distinct difference in this property for the two substances. When measured in the present study the charge from olivine was found to be highly negative but of the same magnitude as that measured for silica bearing dusts in iron foundries.

The body appears to have low tolerance for positive charge or electron deficiency. Most chemical carcinogens require metabolic activation in vivo. The final active forms of chemical carcinogens are electron deficient, electrophilic, or positively charged reagents. These electrophils combine with numerous electron rich components of cellular molecules such as nucleic acids or proteins to form covalently bound carcinogen residues attached to these macromolecules. The binding of the chemical carcinogens to specific informational molecules involved in the control of growth appears to initiate the carcinogenic process, the positively charged reagents being the initiating factors. ${ }^{19}$ Experiments with implanted surface charge have supported this process of initiation. ${ }^{20}$ The mechanism of pathogenesis in the silica reaction at the cellular level has been discussed in detail. ${ }^{21} 22$ Allison's experiments also pointed out that necrosis of the macrophage was not the important step in the sequence culminating in the disease but that fibrogenesis was dose dependent, being greatest when small doses of silica were used. Small doses of 


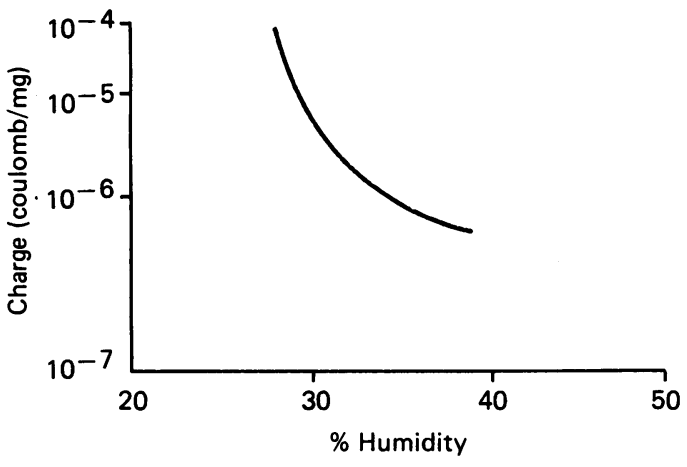

Relation between charge and humidity.

silica stimulated synthesis of macrophage enzymes resulting in fibrogenesis, but did not kill the cells. Higher doses of silica resulted in death of macrophages with little fibrogenesis. The combination of positively charged silica particles with electron rich protein components of macrophages appears to result in the release of collagenase, which activates fibroblasts, through factors, to lay down collagen. The extent of exposure, a product of the number of particles and their charge, could have different kinds of effects on macrophages resulting in different diseases. A higher exposure could kill the macrophages and thus have a more serious effect. It is not surprising, therefore, that foundry workers also show a higher cancer rate than the general population (Dodson V. Personal communication). This could have resulted from an excessive exposure. The same mechanism may be true of other substances that carry a positive charge.

The figure shows that higher values of positive charge were measured when humidity was low. This suggests that keeping the humidity high may help in controlling the charge picked up by the silica particles and thus their toxicity. Humidity would also help in the coalescence of smaller particles to larger ones, possibly making them non-respirable.

\section{Conclusions}

The experimental work and survey of published data suggest that the toxicity of respirable silica particles is caused by the large amount of positive charge they carry. Low humidity tends to increase the magnitude of the charge.

The proposed mechanism is that inhaled silica particles that reach the alveolar regions are taken up by macrophages. These positively charged silica particles combine with specific electron rich protein molecules within the macrophage. This results in the release of collagenase. Fibroblasts are activated through various factors to lay down collagen, an event that could be aggravated by particles carrying positive charges of certain magnitude.

I thank Professor V Dodson, Department of Preventive Medicine and of Medicine, University of Wisconsin at Madison; Mr R Frankenburg, Giddings and Lewis Foundry, Madison; Mr L Wahl, National Institute of Health, Bethesda, Maryland; and Dr Anne Wheldon, University of Reading, England.

1 Agricola, cited by Zaidi SH. Experimental pneumoconiosis. Baltimore: Johns Hopkins Press, 1969.

2 Heppleston AG. Fibrogenic action of silica. Br Med Bull 1969;25:282-7.

3 Kosztolanyi G, Kellermayer N, Jobst K. On the surface potential of pneumoconiotic dusts. Beitrag Pathologie Bänder 1972; 147:42-4.

4 National Institute for Occupational Safety and Health. Criteria standard for occupational exposure to crystalline silica. Cincinnati: NIOSH, 1974.

5 Koski IR, Poplack DG, Blaese RM. A non-specific esterase stain for identification of monocytes and macrophages. In: Bloom $\mathrm{BR}$, David JR, eds. In vitro methods in cell mediated and tumor immunity. London: Academic Press, 1976:359-62.

6 Kaplow LS. Simplified myeloperoxidase stain using benzidine dihydrochloride. Blood 1965;26:215-29.

7 Burrel R, Anderson M. The induction of fibrogenesis by silicatreated alveolar macrophages. Environ Res 1973;6:389-94.

8 Vigliani EC, Permis B. Immunological factors in the pathogenesis of the hyaline tissue of silicosis. $\mathrm{Br} J$ Ind Med 1958; 15:8-14.

9 Crystal RG, Fulmer JD, Baum JD, et al. Cells, collagen and idiopathic pulmonary fibrosis. Lung 1978;155:199-224.

10.Wahl LM, Wahl SM, Mergenhagen SE, Martin GR. Collagenase production by endotoxin-activated macrophages. Proc Natl Acad Sci USA 1974;71:3598-601.

11 Werb Z, Gordon S. Secretion of a specific collagenase by stimulated macrophages. Journal of Experimental Medicine 1975;142:346-60.

12 Brain JD. The effects of increased particles on numbers of alveolar macrophages. In: Walton WH, ed. Inhaled particles III. Surrey: Unwin Bros, 1971:209-31.

13 Gabor S, Frits T, Anca Z. Effects of quartz and asbestos on erythrocyte surface charge. Int Arch Occup Environ Health 1975;36:47-55.

14 Light WG, Wei ET. Surface charge and hemolytic activity of asbestos. Environ Res 1977;13:135-45.

15 Erickson C, Jones S. Effects of small electrical currents on collagen in solution. South African Journal of Science 1976; 36:47-55.

16 Richards RJ, Morris TG. Collagen and mucopolysaccharide production in growing lung fibroblasts exposed to chrysotile asbestos. Life Sci 1973;12:441-51.

17 Bagchi N. A proposed mechanism of the asbestos reaction. Proceedings of the national symposium on air pollution control. New Delhi, India: 1983.

18 Tubich GE. Health aspects of olivine non-ferrous foundry applications. Chicago: American industrial hygiene conference, 1967.

19 Miller JA, Miller EC. Ultimate chemical carcinogens as reactive mutagenic electrophiles. In: Origins of human cancer. Cold Spring Harbor, New York: 1975:605--27.

20 Andrews EJ, Todd PW, Kukulinsky NE. Surface charge in foreign body carcinogenesis. J Biomed Mater Res 1979;13: 173-87.

21 Allison AC. Mechanism of macrophage damage in relation to pathogenesis of some lung diseases. In: Brain JD, Proctor DF Reid LM, eds. Respiratory defense mechanisms. Basel: Marce Decker, 1977:1072-102.

22 Summerton J, Hoenig S, Butler C, Chvapil M. The mechanism of hemolysis by silica and its bearing on silicosis. Journal of Experimental and Molecular Pathology 1977;26:113-28.

Accepted 8 July 1991 